\title{
El laberinto de los discursos del Buen vivir: entre Sumak Kawsay y Socialismo del siglo XXI
}

\author{
Julien Vanhulst \\ Universidad Católica del Maule, Talca, Chile. \\ Email: julien@ucm.cl
}

Resumen: En el presente artículo, se propone un análisis en profundidad de los discursos del Buen vivir. Ponemos de relieve el interés contemporáneo por esta nueva propuesta en el campo discursivo del desarrollo sustentable. Identificamos los actores que sostienen este discurso y revisamos su construcción histórica, derivada de la combinación de principios cosmológicos de los pueblos indígenas de América Latina, de las contribuciones contemporáneas de algunos intelectuales críticos (latino-americanos e internacionales) así como de su inclusión en la esfera política y su institucionalización parcial (principalmente en Ecuador y Bolivia). También consideraremos la manera de concebir la modernidad y la cuestión fundamental de la sustentabilidad socio-ambiental; así como las tensiones entre los discursos normativos y las prácticas neo-extractivistas vigentes en América Latina. Finalmente, este análisis permite distinguir tres grandes corrientes del Buen vivir: las corrientes “Indigenista”, “Socialista” y "Post-estructuralista” en función de los modos de problematizar la modernidad y la sustentabilidad.

Palabras clave: corriente indigenista, corriente socialista, corriente postestructuralista

\section{The labyrinth of discourses about Buenvivir: between Sumak Kawsay and Socialism of the XXI century}

\begin{abstract}
This paper proposes an in-depth analysis of the discourses of the Buen vivir. We underline the contemporary interest for this new proposal in the discursive field of sustainable development. We identify the actors that support this proposal and review its historical construction, derived from the combination of cosmological principles of indigenous people of Latin America, contemporary contributions of some critical intellectuals (Latin American and international) and its inclusion in the political sphere and partial institutionalization (mainly in Ecuador and Bolivia). We also consider the way they conceive modernity and the fundamental question of socio-environmental sustainability; as well as the tensions between normative discourses and neo-extractive practices in Latin America. Finally, this analysis suggests a distinction between three main currents of the Buenvivir: the "Indigenist", "Socialist" and "Post-structuralist" currents according to their modes of problematizing modernity and sustainability.
\end{abstract}

Keywords: Indigenist current, socialist current, post-structuralist current 


\section{O Labirinto de discursos do Bom Viver: entre Sumak Kawsay e Socialismo do século XXI}

Resumo: Nestetrabalho, umaanálise é propostaemprofundidade os discursos do BomViver. Enfatizamos o interessecontemporâneo na nova proposta no campo discursivo do desenvolvimentosustentável. Nós identificamos os atores que têmestavisão e rever o seuconstrução histórica, derivados da combinação de princípios cosmológicos dos povos indígenas da América Latina, as contribuiçõescontemporâneas de algunsintelectuais críticos (Literatura Latino-Americana e internacionais) e suainclusão no esfera política e suainstitucionalização parcial (principalmente no Equador e Bolívia). Também vamos estudar a forma de conceber a modernidade e a questão fundamental da sustentabilidadesócio-ambiental; e as tensões entre discurso normativo e práticas neo-extrativismoem vigor na América Latina. Finalmente, esta análise pode distinguir trêscorrentesprincipais de boa vida. O "índio", "socialista" e "pós-estruturalista" de acordocom as formas de problematizar correntesmodernidade e sustentabilidade. estruturalista

Palavras-chave: corrente socialista, corrente indigenista, correntepós-

$* * *$

\section{Introducción}

En la segunda mitad del siglo XX, la emergencia del problema fundamental de la sustentabilidad socio-ambiental ha abierto un espacio discursivo compuesto por múltiples respuestas más o menos críticas. A pesar de esta proliferación de discurso a nivel normativo, su implementación no ha dado lugar a los cambios necesarios y suficientes a escala individual y colectiva, y los patrones de producción y consumo de la humanidad siguen social y ambientalmente deletéreos(véase entre otros los informes del IPCC, 2014; Steffen \& al., 2015; United Nations, 2014, para una visión de conjunto actualizada de la situación social y ambiental a nivel mundial). En este contexto, a partir de la experiencia latinoamericana, una red de actores transnacionales ha articulado un proyecto alternativo que intenta apartarse del paradigma dominante del desarrollo y acercarse a un nuevo horizonte: el del "Buen vivir".

En este artículo, se propone un análisis de los discursos construidos en torno al ideal del Buen vivir en América Latina; esto con el fin de explorar más en profundidad no sólo su lugar en el campo discursivo del desarrollo sustentable y los actores que lo usan, pero también su significado, su singularidad y sus vínculos con la experiencia histórica y las prácticas de los actores sociales en América Latina. Describiremos y contextualizaremos la emergencia histórica de este discurso, su contenido y su performatividad pero también las contradicciones derivadas de su cooptación por diferentes actores. También distinguiremos tres corrientes que permiten categorizar 
la multiplicidad de discursos del Buen vivir según su concepción de la modernidad y del desarrollo sustentable (en conexión directa con tres modos de concebir la modernidad: el universalismo, el particularismo, el pluralismo ${ }^{1}$; y las clasificaciones propuestas por John Dryzek (2005) y Bill Hopwood y al.(2005) para las concepciones del desarrollo sustentable).

\section{Los discursos del Buen vivir en el campo discursivo del desarrollo sustentable}

En el conjunto de los discursos del desarrollo sustentable articulados por los autores latinoamericanos, uno de los discursos emergentes en los últimos cinco años es el del Buen vivir. Este discurso se inscribe en el campo discursivo global del desarrollo sustentable, ya que considera el problema fundamental de la sustentabilidad (la relación de dependencia mutua entre la humanidad y el medio ambiente) de una manera específica. Como lo veremos, a medida que se confirma la instalación de este nuevo discurso en el paisaje normativo y en ciertas prácticas sociopolíticas, su contenido se diversifica. Así, se convirtió en un sub-campo en el campo discursivo global del desarrollo sustentable, una subcategoría que incluye una serie de discursos más o menos análogos construidos por las colectividades que lo han adoptado y adaptado. Podríamos entonces hablar de los discursos del Buen vivir (Capitán \& Guevara, 2014; Cubillo-Guevara, Hidalgo-Capitán, \& Domínguez-Gómez, 2014; Gudynas, 2013; Hidalgo-Capitán \& al., 2012; Loera González, 2015). De hecho, no hay una definición estricta del Buen vivir. Es probablemente también lo que le da fuerza.

Así, Eduardo Gudynas (2011) habla del Buen vivir como un proyecto en construcción más parecido a una plataforma que a un concepto claro y preciso. A modo de ejemplo, en este conjunto, la idea de Buen vivir declarada por el Presidente de Bolivia, Evo Morales, se parece a un proyecto político de descolonización, mientras que la de Rafael Correa, Presidente de Ecuador, se asimila más y más al proyecto del socialismo del siglo XXI (implementado principalmente en Venezuela, Bolivia y Ecuador) que perpetúa el modelo de desarrollo extractivista pero reorienta los beneficios hacia políticas sociales ("progresistas”) y una mejor redistribución de las riquezas. Esta perspectiva está muy lejana a la del economista ecuatoriano Alberto Acosta (Presidente de la Asamblea Constituyente de 2008 y candidato presidencial en 2013), que propone una definición más fiel a la cosmovisión indígena y centrada en los derechos, incluyendo los derechos de la naturaleza. Así distinguimos diferentes corrientes y tipos de discurso del Buen vivir.

En el campo académico en América Latina, el Buen vivir está evocado por varios autores más o menos centrales como David Barkin, Arturo Escobar, Edgardo Lander, Héctor Alimonda, Leonardo Boff, Antonio Elizalde, Enrique Leff o aún Gustavo Esteva; y sus principales representantes son Alberto Acosta y Eduardo Gudynas. 
Por otro lado, podemos observar que el Buen vivir conoce una cierta resonancia internacional, en particular con el proyecto Yasuní-ITT (ver más abajo), pero más ampliamente como discurso alternativo y propuesta crítica al problema de la sustentabilidad desde América Latina. Así, ampliando el espectro más allá del discurso regional, podemos apreciar el creciente interés por el discurso del Buen vivir a nivel internacional mediante la revisión del número de publicaciones académicas que contienen la palabra clave "Buen vivir" en su título y el número de publicaciones que las citan:

\section{Gráfico 1 - Publicaciones y citas de artículos sobre el Buen vivir en el mundo desde 2000}

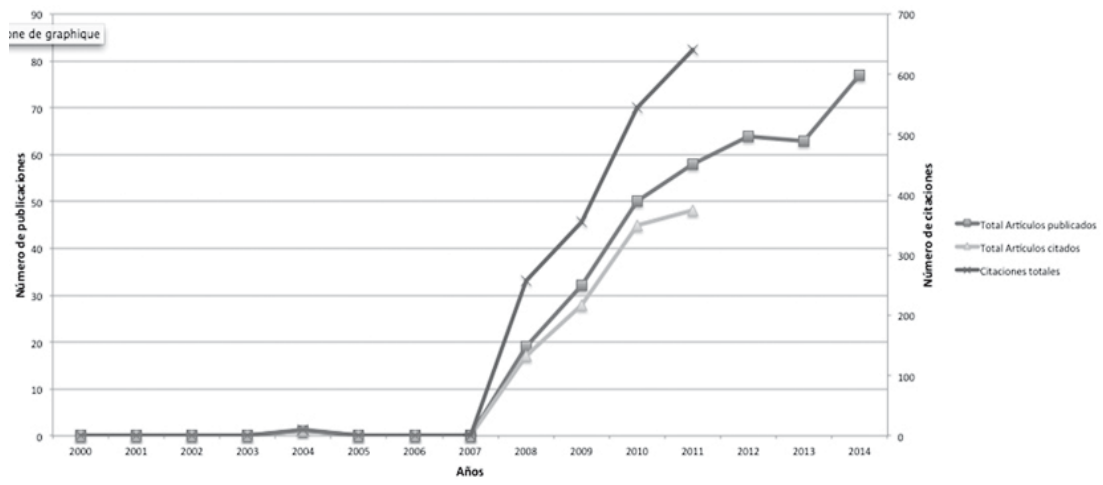

Fuente: realizado por el autor a partir de los datos de la base de datos de Google Académico extraídos con el software Publish or Perish en enero de 2015

Tenemos una primera publicación en 2004². Se trata del libro "Aprender en la sabiduría y el Buen vivir", publicado por la UNESCO en 2004 (García, Lozano, Olivera, \& Ruiz, 2004), y que se interesa en la iniciativa educativa ecuatoriana de la "Universidad Intercultural de las Nacionalidades y Pueblos Indígenas Amawtay Wasi”, que busca revalorizar y reinscribir la cosmovisión, la epistemología y la ética indígena al centro de la educación superior. Pero como vemos, la construcción académica de los discursos del Buen vivir empieza más específicamente hacia 2008 (año de las negociaciones multilaterales de la Asamblea Constitucional) y adquiere desde entonces una cierta importancia internacional con un crecimiento sostenido de las publicaciones (60 artículos publicados cada año y citados por la comunidad académica desde 2010). Así, no sólo el número de publicaciones aumenta con el tiempo, sino también el número de citas y de artículos citados. Por otro lado, si inicialmente los documentos son publicados por editoriales y / o revistas latinoamericanas (como la revista América Latina en Movimiento o la editorial CAAP, Centro Andino Acción Popular, i.a.) las publicaciones referenciadas ya no se limitan sólo a los canales de comunicación y redes latinoamericanas y están presentes en diversas 
revistas internacionales (como la revista Development o Ecological Economics que se abrieron al diálogo con el discurso del Buen vivir) y en diferentes idiomas. A partir de estos elementos de análisis, podemos afirmar que este discurso es relativamente importante en la esfera académica y que se volvió influyente a nivel internacional.

Finalmente, los discursos críticos (y a menudo centrales en la red académica latinoamericana) son generalmente los menos performativos al nivel de las políticas públicas. Como lo hemos indicado, las soluciones institucionalizadas para responder al problema de la sustentabilidad son generalmente más cercanas al discurso de la modernización ecológica, y articuladas en torno a reformas incrementales. Considerando lo anterior, los discursos del Buen vivir son interesantes ya que se trata de discursos críticos transformacionistas y que han tenido un cierto grado de institucionalización, principalmente en Ecuador y Bolivia.

\section{La triple hélice de los discursos del Buen vivir}

Los discursos del Buen vivir aparecen en América Latina, favorecidos por una coyuntura histórica singular. En la década de 1990, frente a la orientación neoliberal de los gobiernos post-autoritarios, diferentes movimientos socio-políticos han surgido en varios países de América Latina. Aunque estos procesos son muy complejos y que sería necesario matizar las situaciones en los diferentes países, se admite que marcaron un giro histórico hacia políticas “progresistas” o “post-neoliberales” (Yashar, 2005). Este giro ha dado lugar a una emancipación política inédita de grupos sociales históricamente marginados, y en particular de los pueblos autóctonos, especialmente en Bolivia y Ecuador, donde estos grupos étnicos representan una parte importante de la población. Por otra parte, estas transformaciones aparecen simultáneamente al fortalecimiento de movimientos sociales internacionales anti-/alter globalización así como los movimientos ambientalistas que entrarán en convergencia con los movimientos indígenas. Por último, el tercer factor que contribuye a la eclosión de los discursos del Buen vivir es el desencantamiento creciente frente al ideal del desarrollo y la búsqueda de modelos alternativos.

Según Eduardo Gudynas y Alberto Acosta, el Buen vivir se puede definir (muy abiertamente) como una "oportunidad para construir otra sociedad sustentada en la convivencia del ser humano en diversidad y armonía con la naturaleza, a partir del reconocimiento de los diversos valores culturales existentes en cada país y en el mundo" (Gudynas \& Acosta, 2011: p. 103). Como discurso alternativo a las versiones dominantes de desarrollo, es el resultado de una combinación particular entre (1) ciertos principios éticos de la antigua cultura andina (defendidos por los movimientos indígenas), (2) las contribuciones contemporáneas de algunos intelectuales críticos y (3) la incorporación liminar de estos principios en la esfera política, lo que es particularmente visible en Ecuador y Bolivia, que incluyeron el Buen vivir en sus nuevas constituciones. Esta subdivisión coincide con la 
tipología propuesta por Luis Antonio Hidalgo-Capitán en su análisis de la emergencia y múltiples apropiaciones del concepto (Capitán y Guevara, 2014. Cubillo-Guevara \& al, 2014; Hidalgo-Capitán \& al, 2012). A partir de ella, se propone agrupar las diferentes aproximaciones contemporáneas del Buen vivir en 3 grupos: (1) la corriente "Indigenista" (caracterizada por la importancia dada a la autodeterminación de los pueblos indígenas), (2) la corriente "Post-estructuralista" (principalmente representada por algunos intelectuales progresistas de América Latina y Europa cercanos al ambientalismo y otros movimientos sociales) y (3) la corriente "Socialista" (caracterizada por la importancia dada a la gestión de la política estatal del Buen vivir, así como a la equidad social, dejando a los temas ambientales, culturales y de identidad en segundo plano).

En este conjunto heterogéneo, podemos distinguir cuatro elementos básicos constitutivos del discurso del Buen vivir: (a) la idea de armonía con la naturaleza (incluyendo los componentes abióticos); (b) la reivindicación de los principios y valores de los pueblos marginados/subordinados ; (c) el Estado garante de la satisfacción de las necesidades básicas (como la educación, la salud, la alimentación y el agua), de la justicia social y de la igualdad; y (d) en última instancia la democracia. Además hay dos líneas de fondo transversales: el Buen vivir como paradigma crítico de la modernidad eurocéntrica (antropocéntrica, capitalista, economicista y universalista) y como nuevo proyecto político intercultural. A partir de estos elementos constitutivos del discurso, vemos como este proyecto se inscribe en los cambios post-neoliberales que tratan de reubicar el Estado en el centro de la gestión de la vida pública y revalorizar el conocimiento y las prácticas indígenas. Por lo tanto, es evidente que varias dimensiones identificadas aquí no son específicas del discurso del Buen vivir y dependen más directamente de la coyuntura política particular de países como Ecuador y Bolivia. Por el contrario, el vínculo explícito entre justicia social, valorización de los saberes y prácticas subordinadas e inclusión del medio ambiente es particular (y esta combinación proviene en parte de herencias intelectuales sobre el desarrollo y la modernidad en el contexto latinoamericano). En este sentido, los discursos del Buen vivir traen una nueva perspectiva a los desafíos del desarrollo sustentable en los planos económico, social y ambiental.

Los discursos del Buen vivir incluyen la idea de interdependencia entre la sociedad y su entorno natural, simbolizada por la Pachamama o "Madre Tierra” y una concepción de la cultura como una realidad plural. Implica una ruptura fundamental con las ideologías occidentales modernas y principalmente las del dualismo sociedad-naturaleza y el universalismo eurocéntrico (y las dicotomías que se derivan de ellos). Del mismo modo, el Buen vivir no es comparable a la idea occidental de progreso continuo para acceder al bienestar, donde la idea de "progreso" reenvía a un futuro indefinido. Propone más bien pensar una forma de vivir el presente en armonía, es decir, asumiendo y respetando las diferencias y complementariedades (entre humanos y entre humanos y no humanos) desde un punto de vista ecológico que podría ser descrito como holístico y mutualista. Así, el Buen vivir rompe con una visión del mundo cartesiana y reduccionista para adop- 
tar una perspectiva sistémica que abarca el conjunto de la ecosfera (incluidos sus componentes abióticos) en una perspectiva ecocéntrica o “biocéntrica”. Por supuesto, esta perspectiva no es exclusiva de los discursos del Buen vivir. Encontramos el mismo tipo de argumentos en varios discursos críticos de la división entre naturaleza y cultura. Se encuentra por ejemplo en los desarrollos teóricos de Bruno Latour sobre la modernidad, de Philippe Descola sobre la antropología natural o aún de los representantes de la sociología ambiental. A un nivel más general, esta crítica de la división de Sociedad/Naturaleza es el tema central de la ética ambiental (que busca reinterpretar la relación entre los seres humanos y el medio ambiente desde el punto de vista moral) y de la ecología política (que considera la naturaleza como la condición objetiva de la existencia de las sociedades humanas y debiera por consiguiente ser considerada como parte del espacio público y sujeto político). Por último, la mayoría de los discursos potencialmente incluidos en la categoría "Transformacionista”" de Hopwood \& al. (2005),en el conjunto del campo discursivo del desarrollo sustentable, hacen eco a las críticas de Buen vivir hacia las concepciones eurocéntricas, antropocéntricas o cartesianas del desarrollo sustentable (aunque, como veremos, las versiones "socialistas" del Buen vivir, desarrolladas e implementadas por los gobiernos de Ecuador y Bolivia son más bien reformistas y menos orientadas al ecocentrismo que las versiones “indigenistas" y "post-estructuralistas").

Los discursos del Buen vivir se alejan de la idea de homogeneidad cultural y social, asumiendo su imposibilidad lógica en un mundo diverso, y proponen a cambio abrir una vía armónica de "unidad en la diversidad". Esta dimensión del Buen vivir resuena con las teorías pluralistas de la modernidad. Siguiendo este criterio, veremos que las apropiaciones del discurso del Buen vivir oscilan entre aproximaciones más radicales, y cercanas a las perspectivas particularistas (más volcadas a un tipo de esencialismo del Buen vivir), y otras más moderadas que se asemejan más al pluralismo. De hecho, como lo hemos visto, el Buen vivir ha encontrado un cierto interés fuera de las fronteras andinas; y algunas interpretaciones proponen explícitamente transponerlo a escala global bajo un prisma pluralista (Kauffman \& Martin, 2014; SENPLADES, 2013: p. 8).

\section{Orígenes indígenas: la corriente "indigenista” del Buen vivir}

La noción de “Buen vivir” es una extrapolación del concepto quechua "Sumak Kawsay" y nociones similares de otros pueblos indígenas de América Latina: el "Suma Qamaña” de los aymaras, el "Ñandereko” de los guaranís, el "Shiir waras” de los achuar o aún el "Küme Mongen” mapuche, entre otros (Jiménez, 2011). En términos generales, estos conceptos indígenas convergen en un principio que se puede resumir de la siguiente manera: "vivir en armonía y equilibrio; en armonía con los ciclos de la Madre Tierra, del cosmos, de la vida y de la historia, y en equilibrio con toda forma de existencia” (Huanacuni Mamani, 2010: p. 32). Sin embargo, esta transposición es reductora y no permite dar cuenta de la profundidad semántica del concepto original, el cual, en la cosmología indígena, es un principio de 
vida, plenitud, y una guía para la acción (para mayor detalles ver Beling, Gomez, \& Vanhulst, 2014).

Es importante subrayar que se trata de un principio como el de "igualdad” o de “democracia”. De hecho, conviene no caer en una concepción idealizada de las culturas indígenas y en el imaginario colectivo que las percibe como a-conflictivas y horizontales. El mundo indígena no era (y no está) exento de problemas, conflictos y diversas formas de dominación y asimetrías. Por lo tanto, los discursos contemporáneos del Buen vivir se inspiran (con mayor o menor fuerza) de principios tradicionales reconstruidos, reinventados por los actores sociales contemporáneos (indígenas y no indígenas) que buscan redefinir las trayectorias de desarrollo.

Esta dimensión inscribe el Buen vivir en el conjunto más amplio de los movimientos sociales indígenas de finales del siglo XX. Como fue ya mencionado, en la década de 1990, en varios países de América Latina, los proyectos de políticas neoliberales enfrentaron importantes reacciones populares (Yashar, 2005). Estas tensiones derivan entre otras razones de la marginación histórica de los pueblos indígenas no sólo en la época de las colonias, sino también durante la época republicana. De hecho, en el contexto de las transformaciones sociopolíticas que instauran las Repúblicas en América Latina, las sociedades indígenas estaban consideradas como anacrónicas y parasitaban la proyección de una imagen de nación "moderna” a nivel internacional. A pesar de estas fuertes presiones, los pueblos indígenas fueron capaces de perpetuar sus tradiciones y organizarse para resistir frente a múltiples formas de violencia física y simbólica. Así, los movimientos modernizadores de tendencia eurocéntrica comparten con diversas formas de nativismo. A la salida de los regímenes militares de finales del siglo XX, los pueblos indígenas de América Latina van a organizarse y establecer un movimiento social capaz de introducir un contrapeso en los debates políticos a nivel nacional, regional y mundial. En estos procesos, las comunidades indígenas organizadas a nivel nacional (por ejemplo, la $\mathrm{CONAIE}^{4}$ en Ecuador o la $\mathrm{CIDOB}^{5}$ en Bolivia) y, más recientemente, a nivel regional (la $\mathrm{CAOI}^{6}$ ), se convirtieron en actores políticos esenciales en la construcción de nuevos Estados. El surgimiento de las voces indígenas aparece no sólo como una reacción de las comunidades indígenas de los países andinos a los regímenes neoliberales, sino también como el resultado de la convergencia entre las cosmovisiones indígenas y la ideología de los distintos movimientos sociales globales de finales del siglo XX, especialmente los movimientos: anti-/alter-globalización; por los derechos humanos; y ambientales ${ }^{7}$. Así, a partir de sus experiencias particulares, los movimientos indígenas de América Latina de finales del siglo XX participan del debate global que nace de la crisis de la modernidad eurocéntrica. Se constituye entonces como un movimiento social regional profundamente comprometido con una crítica de los procesos políticos y sociales globales.

La Declaración de Cuzco (proveniente de la reunión de los pueblos indígenas de julio 2006 que funda la CAOI) incluye los principales temas de tensión y de reivindicación desde los años 1980-1990, y entre otros: la 
construcción de Estados plurinacionales (que permiten el respeto y el reconocimiento de las diferentes culturas, pueblos y nacionalidades); la defensa de los recursos naturales y, más generalmente de la Pachamama; los derechos colectivos de las comunidades indígenas; y la autodeterminación de los pueblos. Estos elementos de lucha serán reafirmados en el octavo Foro Social Mundial de Belém ${ }^{8}$ y reiterados en numerosas cumbres internacionales. Formalmente, desde finales de la década de 2000 Bolivia y Ecuador han instalado diferentes procesos históricos que permitieron encarnar estos principios. Por ejemplo, la Constitución de 2009 de Bolivia establece en su primer artículo: “Bolivia se constituye en un Estado Unitario Social de Derecho Plurinacional Comunitario, libre, independiente, soberano, democrático, intercultural, descentralizado y con autonomías. Bolivia se funda en la pluralidad y el pluralismo político, económico, jurídico, cultural y lingüístico, dentro del proceso integrador del país”. Encontramos ahí varios elementos defendidos por los movimientos indígenas (a pesar de que la implementación concreta de estos principios sigue todavía en entredicho).

El Buen vivir reúne en un bloque diferentes elementos socio-ambientales de las reivindicaciones indígenas y se conglomera con los discursos críticos internacionales. Deriva directamente de estos movimientos indígenas y al mismo tiempo el discurso del Buen vivir retro-alimenta estos mismos movimientos (reafirmando el interés y simultáneamente la legitimidad, de los estilos de vida y valores indígenas en la búsqueda de la sustentabilidad). En el ámbito académico, este componente indígena forja la corriente “indigenista” del Buen vivir. Esta corriente se caracteriza especialmente por la importancia dada a la autodeterminación de los pueblos indígenas y a las cosmovisiones indígenas. Se utiliza más particularmente el término de "Sumak Kawsay" (u otros afines) y menos el de "Buen vivir", siendo este último a veces considerado como una distorsión occidental de los principios originales indígenas (Macas, 2010; Maldonado, 2010; Oviedo Freire, 2013, 2014). Estas versiones del Buen vivir tienden a acercarse a unas versiones particularistas de la modernidad. En este sentido, la crítica de la modernidad eurocéntrica invita a salir de la modernidad y rehabilitar las creencias y modelos culturales de los pueblos indígenas, incluida la relación con la Pachamama. Los modos de inclusión de la sustentabilidad se acercan a versiones eco-céntricas y a formas de radicalismo verde, tal como fueron tipificadas por John Dryzek (2005), como un discurso que busca una nueva sensibilidad ecológica y rechaza la estructura de la sociedad industrial y su concepción del medio ambiente (aunque en el caso de las versiones indigenistas del Buen vivir, es menos una "nueva sensibilidad” que la búsqueda de un retorno a las supuestas sensibilidades tradicionales de los pueblos indígenas). Entre los principales representantes de esta corriente, encontramos algunos líderes indígenas de Ecuador, Bolivia y Perú, así como algunos indigenistas e intelectuales particularistas (entre otros: Carlos Viteri, Simón Yampara, Javier Medina, Nina Pacari, Luis Macas, David Choquehuanca, Fernando Huanacuni Pablo Dávalos, etc.). Para ellos, el Sumak Kawsayno se presenta como un “desarrollo alternativo” porque rechazan completamente la modernidad (eurocéntrica) y consideran el desarrollo como uno de sus atributos. Como hemos señalado, la idea de pro- 
greso es ajena a la cosmovisión andina, por lo tanto, el Sumak Kawsay no se presenta como una variante del desarrollo, sino como una "alternativa al desarrollo” (Gudynas, 2014b).

Sin embargo, la atención actual hacia el Buen vivir resulta de un doble proceso, de emancipación de sus orígenes en las cosmologías indígenas, y de la conceptualización académica y política que constituye la base de este discurso contemporáneo, que lo separa del indigenismo y lo posiciona en las interacciones discursivas en torno al imperativo de la sustentabilidad.

\section{Entrada en la esfera política: la corriente “socialista” del Buen vivir}

En general, la definición y la aplicación de nuevas normas e instituciones resultan de desarrollos complejos que combinan procesos "Topdown" y "Bottom-up". Las estrategias top-down apuntan a responder a objetivos establecidos a niveles supranacionales que se imponen de manera más o menos vinculante en los países. Los movimientos bottom-up provienen de la base, de la sociedad civil y pueden influir potencialmente las políticas nacionales y eventualmente cruzar las fronteras. Encontramos estos dos tipos de procesos en la evolución de la gobernanza ambiental en Ecuador y Bolivia (Kauffman \& Martin, 2014; Martin, 2011; Martin \& Wilmer, 2008). Por ejemplo, la proliferación de parques nacionales, que resultan de propuestas conservacionistas de diversos grupos y redes transnacionales que tuvieron un impacto internacional considerable en el siglo XX, es un proceso top-down; como la creación de instituciones jurídicas y administrativas para la gestión ambiental (que resultan de propuestas de modernización ecológica, ampliamente dominante a nivel global). A modo de ejemplo, el Ministerio de Medio Ambiente se creó en 1996 en Ecuador como parte de la modernización del aparato estatal. Su mandato sigue las principales líneas directrices de Río 1992 y sus distintos programas se refieren directamente a las normas internacionales en materia de descentralización, participación, gestión del medio ambiente, desarrollo de mercados de servicios ambientales, etc. ${ }^{9}$ En paralelo a estas dinámicas, podemos observar que las diferentes organizaciones ambientales locales e internacionales adoptan los principios y programas de los movimientos sociales locales, y entre ellos, el movimiento indígena, en un proceso bottom-up. Este es el caso en Ecuador para la creación de múltiples redes transnacionales y campañas como la iniciativa emblemática Yasuní ITT (ver más abajo), el juicio contra Chevron-Texaco (Joseph, 2012; Kimberling, 2005), o el manejo de la cuenca de Tungurahua (Kauffman \& Martin, 2014), entre otros. Por último, de manera más general, podemos considerar que los elementos de institucionalización del Buen vivir a nivel nacional y su inserción a nivel internacional resultan de un proceso bottom-up, como se defiende aquí.

Hemos subrayadoque la conjugación deprincipios provenientes delas cosmologías de los pueblos autóctonos con ciertosimperativossocio-ambientales globales cristalizaron lentamenteen el discurso del Buen vivir, especialmente en EcuadoryBolivia. Así, elBuen vivir se encuentra al centrode 
las nuevas Constituciones nacionales derivadas delas asambleas constituyentesconvocadasen esos países, así como en el "Plan Nacional para elBuen Vivir2009-2013” en Ecuador (SENPLADES, 2009) y su versiónactual(2013-2017), que fue aprobada en junio de 2013por el ConsejoNacional de Planificación de Ecuador (SENPLADES, 2013).

En la nueva Constitución nacional de Ecuador, la referencia al Buen vivir aparece directamente en el preámbulo, destacando la decisión del país de construir "Una nueva forma de convivencia ciudadana, en diversidad y armonía con la naturaleza, para alcanzar el buen vivir, el sumak kawsay” (p. 15). Además de este alcance transversal, el Buen vivir tiene su propio régimen incluido en los “Derechos del Buen vivir” (Título II - Capítulo II) y en el "Plan del Buen Vivir” (Título VII) con más de 75 artículos que integran diferentes temáticas como el agua y la alimentación, el medio ambiente, la cultura y la ciencia, la educación, la salud, los conocimientos tradicionales, la biodiversidad, etc. La Constitución ecuatoriana también incluye un "Régimen de desarrollo" (Título VI), que se describe como: "el conjunto organizado, sustentable y dinámico de los sistemas económicos, políticos, socio-culturales y ambientales, que garantizan la realización del Buen vivir, del sumak kawsay. [...] El Buen vivir requerirá que las personas, comunidades, pueblos y nacionalidades gocen efectivamente de sus derechos, y ejerzan responsabilidades en el marco de la interculturalidad, del respeto a sus diversidades, y de la convivencia armónica con la naturaleza” (Art. 275).

Como vemos, el "Régimen de desarrollo” y la referencia al Buen vivir se cruzan, apuntando a un nuevo tipo de desarrollo social, político y económico, respetuoso del medio ambiente. Así, a pesar de que se proclama abiertamente como una "alternativa al desarrollo", lo que se observa actualmente en las traducciones políticas es que la relación entre el Buen vivir y el discurso del desarrollo sustentable es más de tipo dialógica. La misma conclusión se puede sacar de la lectura del "Plan Nacional para el Buen Vivir 2009-2013”, que inscribe socio-históricamente el surgimiento del Buen vivir en los proceso de "búsqueda de modos alternativos de vida que han impulsado particularmente los actores sociales de América Latina durante las últimas décadas, demandando reivindicaciones frente al modelo económico neoliberal” (SENPLADES, 2009: p. 10). En ese instrumento de planificación nacional, el Buen vivir se define como "una apuesta de cambio [...] que permita la aplicación de un nuevo paradigma económico cuyo fin no se concentre en los procesos de acumulación material, mecanicista e interminable de bienes, sino que promueva una estrategia económica incluyente, sustentable y democrática. [...] Asimismo, el Buen vivir se construye [...] desde el tránsito del actual antropocentrismo al biopluralismo [...]. Finalmente, el Buen vivir se construye también desde las reivindicaciones por la igualdad y la justicia social, y desde el reconocimiento, la valoración y el diálogo de los pueblos y de sus culturas, saberes y modos de vida" (SENPLADES , 2009: p. 10). En este plan, el Buen vivir y el desarrollo se consideran intercambiables. "El desarrollo es la realización del Buen vivir, y la construcción y realización del Buen vivir concreta la nueva visión del desarrollo humano y social” (Walsh, 2010: p. 19). 
En el último “Plan Nacional para el Buen Vivir 2013-2017”, la referencia al Buen vivir sigue siendo central y abiertamente opuesta al modelo económico neoliberal y al eurocentrismo moderno. En ese instrumento actualizado, el Buen vivir se define como "la forma de vida que permite la felicidad y la permanencia de la diversidad cultural y ambiental; es armonía, igualdad, equidad y solidaridad. No es buscar la opulencia ni el crecimiento económico infinito. [...] Esta idea de la solidaridad social y la redistribución es diferente del ideal aristotélico de la buena vida. Buen vivir es una idea social de la movilización, que va más allá del concepto de desarrollo -en vigor en la tradición occidental- y se asocia con una noción más amplia del progreso. No es un nuevo paradigma de desarrollo, pero en una alternativa social, liberadora, que ofrece otras prioridades de la organización social, diferentes del crecimiento económico implícito simple en el paradigma de desarrollo” (SENPLADES , 2013: p. 6 y 9).

Sin embargo, el Plan de 2013introduce un nuevotipo de semántica acoplando los conceptos de“Buen vivir” y "socialismo" en la frase "socialismo del Buen vivir”. Esta es la ideacentral de laplataforma políticadel Movimiento Alianza PAIS (coalición representadapor el presidente RafaelCorrea), que "articula la lucha por la justicia social, la igualdad y la abolición de los privilegios, con la construcción de una sociedad que respete la diversidad y la naturaleza. En tal sociedad podremos desarrollar nuestras capacidades y vivir digna y libremente. El fin del Socialismo del Buen vivir es defender y fortalecer la sociedad, el trabajo y la vida en todas sus formas. El primer paso es resolver el acceso a bienes, oportunidades y condiciones que garanticen -al individuo, a la colectividad y a las generaciones futuras- una vida digna sin perjudicar a la naturaleza” (SENPLADES, 2013:p16).

Aunque obviamente hay matices que diferencian las experiencias ecuatoriana y boliviana, las bases de la Constitución Política de Bolivia, promulgada el 7 de febrero de 2009, se inscriben también en las orientaciones del discurso del Buen vivir. En esta Constitución, el Suma qamaña o "Vivir bien" también tiene un papel transversal. Aparece en el preámbulo y cruza todo el documento como principio rector, tal como la idea de "economía plural”, que busca valorar las actividades no capitalistas en el conjunto de las actividades económicas: "el modelo económico boliviano es plural y está orientado a mejorar la calidad de vida y el vivir bien de todas las bolivianas y los bolivianos” (Art. 306). Por otra parte, en la Constitución nacional boliviana, la naturaleza no se considera como sujeto de derechos como es el caso en Ecuador. Sin embargo, en diciembre de 2010, el gobierno de Bolivia promulgó una ley (Ley de Derechos de la Madre Tierra), que reconoce "los derechos de la Madre Tierra, así como las obligaciones y deberes del Estado Plurinacional y de la sociedad para garantizar el respeto a estos derechos" (Art. 1).

Como ha sido el caso de muchos discursos transformadores a lo largo de la historia, no es de extrañar que la nueva utopía social y política del Buen vivir no cumpla (todavía) sus promesas en la praxis política, eco- 
nómica y social. Así, a pesar de la importancia de los movimientos sociales y de la instalación de gobiernos autocalificados de izquierda y "postneoliberales” en la América Latina de principios del siglo XXI, en la práctica, las contradicciones entre el Buen vivir y el neo-extractivismo desacredita la capacidad de los gobiernos y movimientos sociales de impugnar efectivamente la omnipotencia de los mercados y sus bases neoliberales (Caria \& Domínguez, 2014a; Gudynas, 2012, 2013; Radcliffe, 2012). A pesar de que existe un programa político que incluye las visiones utópicas de las franjas de la población históricamente desfavorecidos o marginados (invocando, entre otro, el Sumak Kawsay y el Suma Qamaña), los gobiernos del presidente Rafael Correa en Ecuador y Evo Morales en Bolivia siguen una senda más bien centrada en prácticas (neo)-extractivistas (principalmente la explotación de petróleo, pero también la minería a gran escala) y los preceptos del "nuevo desarrollismo" defendido por el economista Ha Joon Chang ; fuente de inspiración reconocida para las propuestas de cambio en la política económica de Rafael Correa (véase Correa, 2012). Esta contradicción entre el discurso y la práctica genera una sensación de decepción e indignación entre quienes comparten la utopía representada por los programas de estos gobiernos en la sociedad civil nacional e internacional (Hollender, 2012).

Esta brecha entre principios e implementación política del Buen vivir se hizo evidente especialmente tras la cancelación de la iniciativa emblemática Yasuní-ITT. Este proyecto había sido lanzado oficialmente en 2010 con un acuerdo internacional y la creación del Fondo Yasuní bajo la tutela del PNUD. Apunta a proteger el parque Yasuní, en la zona comprendida entre los puntos de exploración petrolera Ishpingo, Tambococha y Tiputini (ITT). Esta área fue declarada “zona intangible” en 1998 por el gobierno de Jamil Mahuad con el doble propósito de no intervenir en los territorios de los grupos indígenas de la Amazonía ecuatoriana e impedir la extracción de petróleo en esta reserva de la biosfera. La iniciativa Yasuní-ITT, propuesta por varios ambientalistas y grupos indígenas en el marco de la moratoria contra el petróleo (véase más arriba la nota de pie $n^{\circ} 8$ ) será recuperada por el gobierno de Correa que lanzará un llamado a la comunidad internacional (especialmente en la Cumbre Río+20) para apoyar el proyecto. Sin embargo, el 15 de agosto de 2013, el presidente Correa anunció la cancelación de la iniciativa, invocando argumentos tales como la falta de apoyo de la comunidad internacional y la necesidad de recurrir a las ganancias del petróleo para la lucha contra la pobreza. El fracaso Yasuní-ITT muestra claramente que, al menos por ahora, la lógica neo-extractivista del "Consenso de los Commodities” (Svampa, 2013) prevalece en los programas gubernamentales ante el ideal regulativo del Buen vivir.

Más generalmente, otro elemento motor del plan del Buen vivir es la transformación del sistema de producción basado en una matriz de exportación de materias primas (petróleo, cacao, plátanos, recursos pesqueros, etc.) en una matriz productiva centrada en el conocimiento y la tecnología. A pesar de algunas iniciativas importantes en el campo del desarrollo científico y tecnológico (véase, por ejemplo, el proyecto "Prometeo" 10 o "FLOK 
Society"11), la matriz productiva no ha cambiado mucho y las tendencias muestran más bien un fortalecimiento de los dos modelos de producción históricos (agricultura y ganadería inicialmente y, desde 1972, la explotación de petróleo combinada a la producción de materias primas, reforzando un modelo extractivista). Podemos ver en las tablas 1 y 2 y en el gráfico 2 que la matriz de producción histórica se ha fortalecido en los últimos años (importancia creciente del petróleo y del sector primario en la producción no petrolera).

Tabla1-La producción de petróleo en Ecuador 2000-2013 (en millones de barriles)

\begin{tabular}{|cccc}
\hline Año & $\begin{array}{c}\text { Producción } \\
\text { total }\end{array}$ & $\begin{array}{c}\text { Empresas } \\
\text { públicas }\end{array}$ & $\begin{array}{c}\text { Empresas } \\
\text { privadas }\end{array}$ \\
\hline 2000 & 146 & 85 & 61 \\
\hline 2001 & 148 & 83 & 66 \\
\hline 2002 & 143 & 80 & 63 \\
\hline 2003 & 153 & 74 & 79 \\
\hline 2004 & 192 & 72 & 120 \\
\hline 2005 & 194 & 71 & 123 \\
\hline 2006 & 196 & 90 & 105 \\
\hline 2007 & 187 & 94 & 92 \\
\hline 2008 & 184 & 97 & 87 \\
\hline 2009 & 177 & 103 & 75 \\
\hline 2010 & 177 & 110 & 67 \\
\hline 2011 & 182 & 131 & 52 \\
\hline 2012 & 184 & 134 & 51 \\
\hline 2013 & 192 & 145 & 47 \\
\hline
\end{tabular}

Fuente: Banco Central de Ecuador (2014)l

Tabla2-Evolución de las exportaciones primarias en Ecuador 2009-2013 (millones de dólares)

\begin{tabular}{cccccc}
\hline Año & $\begin{array}{c}\text { Exportaciones } \\
\text { primarias }\end{array}$ & \% del total & $\begin{array}{c}\text { Exportaciones } \\
\text { industriales }\end{array}$ & \% del total & $\begin{array}{c}\text { Exportaciones } \\
\text { totales }\end{array}$ \\
\hline 2009 & 10.525 & $75,9 \%$ & 3.338 & $24,1 \%$ & 13.863 \\
\hline 2010 & 13.521 & $77,3 \%$ & 3.969 & $22,7 \%$ & 17.490 \\
\hline 2011 & 17.337 & $77,7 \%$ & 4.986 & $22,3 \%$ & 22.323 \\
\hline 2012 & 18.377 & $77,3 \%$ & 5.388 & $22,7 \%$ & 23.765 \\
\hline 2013 & 20.166 & $80,8 \%$ & 4.792 & $19,2 \%$ & 24.958 \\
\hline
\end{tabular}

Fuente: Caria \& Domínguez (2014b) a partir de PROECUADOR Boletín comercial 


\section{Gráfico2 -Las exportaciones no petroleras en Ecuador (enero-octubre de 2014)}

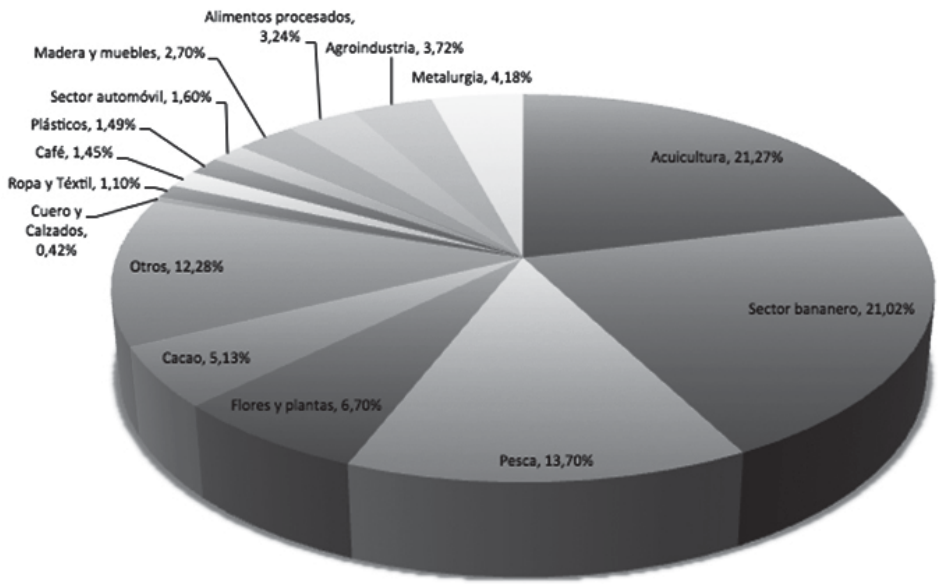

Fuente: elaboración personal en base a PROECUADOR (2014)

Los datos de las tablas 1 y 2 muestran claramente que la importancia del petróleo ha aumentado en los últimos años (y que las empresas públicas han desempeñado un papel importante en esta tendencia). El gráfico 2 muestra que, exceptuando el petróleo, los productos de la agricultura y la ganadería (acuicultura y pesca, sector bananero, cacao, etc.) representan la mayoría de la matriz de producción. En resumen, el cambio hacia una matriz más favorable al medio ambiente no está en curso. Más allá de la retórica política y de los anuncios de cambios radicales, la matriz de producción extractivista y los patrones de acumulación históricos se mantienen.

A partir de los elementos constitutivos del Buen vivir resaltados (armonía con la naturaleza, valoración de los pueblos marginados, la democracia y garantizar la satisfacción de las necesidades básicas, además de la crítica post-eurocéntrica y la interculturalidad), y a la luz de las políticas públicas implementadas desde 2008, sólo las necesidades básicas han encontrado avances significativos. La idea central de la armonía con la naturaleza y la inclusión de valores y prácticas de los grupos marginados no ha tenido el mismo éxito. Hemos visto algunas evidencias que contradicen el principio de la armonía con la naturaleza.

En cuanto a la inclusión de los valores y prácticas de los pueblos ancestrales, la alianza inicial del gobierno de Correa con los grupos indígenas se ha transformado poco a poco en conflicto. En 2010, a raíz de un desacuerdo sobre la Ley de Aguas, el Movimiento Pachakutik y el Movi- 
miento Popular Democrático abandonan la coalición gubernamental. Desde entonces, las relaciones entre el gobierno de Correa y las organizaciones indígenas (especialmente la CONAIE y el Pachakutik) se deterioraron. Una vez más, el caso Yasuní ilustra estas tensiones y contradicciones. La cancelación del proyecto no sólo contradice el principio de armonía con la naturaleza, sino también viola el artículo 57 de la Constitución que establece que "los territorios de los pueblos en aislamiento voluntario son de posesión ancestral irreductible e intangible, y en ellos estará vedada todo tipo de actividad extractiva”. Y, más allá de la iniciativa Yasuní, el gobierno no implementa el mecanismo de consulta ciudadana previsto en la Constitución para los planes de exploración, explotación y comercialización de recursos no renovables que afectan a los residentes. Frente a estas paradojas, Boaventura de Sousa Santos dice que en vez de socialismo del siglo XXI, se trata de un proyecto de "capitalismo del siglo XXI" (de Sousa Santos, 2014).

Por supuesto, estos elementos no invalidan el Buen vivir como discurso, o como utopía (“ilusión movilizadora” según Fander Falconí, “utopía realista” según René Ramírez). De hecho, esta nueva utopía ofrece una cierta cohesión social y una identidad colectiva a diferentes grupos étnicos y sociales. Como lo hemos visto, la idea sigue viva, no sólo para sus representantes originales en Ecuador y Bolivia, sino también para nuevos actores regionales e internacionales que están buscando alternativas viables al discurso dominante del desarrollo basado en la racionalidad económica y el ideal moderno europeo de progreso.

Estos comienzos de institucionalización y estas hibridaciones con la esfera pública consolidan la corriente "socialista" o "estatista" del Buen vivir. Esta segunda corriente se caracteriza por la importancia dada a la gestión pública del Buen vivir que enfatiza más en la equidad social y deja en segundo plano las cuestiones medioambiental, cultural y de identidad. Los representantes de este discurso hablan más específicamente de socialismo del Buen vivir como variante andina del socialismo. Estas ideas no se reducen al contexto indígena y se hibridan más o menos explícitamente con las teorías neo-marxistas, tales como el "socialismo del siglo XXI”, la idea de "Revolución ciudadana" defendida por la coalición Alianza PAIS en Ecuador, la "Economía social y solidaria", así como otras formas de resistencia a la globalización (ver entre otros Amin \& Houtart, 2002) ; que buscan instituir un nuevo sistema socio-económico post-capitalista. Entre los principales representantes de esta versión del discurso del Buen vivir podemos incluir algunos intelectuales latinoamericanos (José Luis Coraggio, Álvaro García Linera, etc.) y europeos (Michael Löwy, François Houtart, etc.) y algunos intelectuales directamente relacionados con los gobiernos progresistas de Ecuador y Bolivia (como Fander Falconí, René Ramírez, Alvaro García Linera, Pedro Páez, Ricardo Patiño, etc.).

Según esta corriente, el Buen vivir es una propuesta racional de desarrollo que da prioridad a las cuestiones de equidad social, considerando en segundo plano el imperativo de la sustentabilidad. Por lo tanto, no 
rechaza la modernidad como lo hace la corriente indigenista y se inscribe más claramente en una corriente más bien universalista (y más particularmente en las propuestas y medidas del desarrollo tales como definidas a nivel mundial en términos de PIB, pero también de calidad de vida, de satisfacción de necesidades básicas, etc.). Esta versión del Buen vivir, muy cercana a las versiones clásicas de desarrollo (y eventualmente sus versiones post-capitalistas) es criticada por los intelectuales ecologistas, así como por los intelectuales cercanos a la corriente del post-desarrollo (Acosta, 2013; Fernández, Pardo, \& Salamanca, 2014; Gudynas, 2010, 2011, 2014a, 2014b; Martinez-Alier, 2008; Svampa, 2013). En el campo discursivo del desarrollo sustentable, en relación con la propuesta Hopwood y al. (2005), con esta corriente socialista, estaríamos más bien en una zona reformista (que propone revisar los atributos de la sociedad industrial sin realizar un cambio radical) pero casi fuera del campo del desarrollo sustentable. Como se ha indicado, la prioridad está en la equidad social y, entonces, más bien en el eje socioeconómico que en cuestiones propiamente ambientales. Se centra en preocupaciones más antropocéntricas (con una cierta disposición a sacrificar algunos acuerdos adquiridos con las comunidades y organizaciones ambientales para el bien social). En relación con la tipología de John Dryzek (2005), esta corriente oscila entre el "Racionalismo administrativo y económico” (que deja la decisión a los expertos y a los mercados más que a los ciudadanos) y la "modernización ecológica” (que redefine la oposición entre economía y medio ambiente de manera positiva y ofrece recetas tecno-científicas para responder a los imperativos de la sustentabilidad, como se puede apreciar concretamente en el caso de la iniciativa Yasuní-ITT).

\section{Conexión conla esfera académica: la corriente“post-estructuralista” del Buen vivir}

Simultáneamente a su difusión en la esfera política, el Buen vivir alimenta ciertas discusiones en la esfera académica ${ }^{12}$, las cuáles retroalimentan la construcción de los discursos del Buen vivir. En general, en la esfera académica, el Buen vivir se caracteriza como el negativo del desarrollo (generalmente asociado a la concepción eurocéntrica). Es este aspecto, junto con su potencial "descolonizador", "alternativo" o "utópico" el que anima la reflexión intelectual en torno a este nuevo discurso. Como lo hemos visto, las definiciones políticas se diluyen en un socialismo del Buen vivir relativamente lejano del Sumak Kawsay defendido por las posiciones indigenistas. Frente a estas dos corrientes, la esfera académica tiene una cierta heterogeneidad en los modos de construcción del Buen vivir. De hecho, podemos distinguir una posición radical que refuerza una tendencia particularista (en gran medida anti-moderna) y una posición moderada (potencialmente dialógica y pluralista).

De acuerdo con laprimera posición, el Buen vivir no se diferencia desus orígenesancestralestipificadosen el Sumak Kawsay. Al contrario, en el surco dela posición indigenista radical, el Buen vivir es considerado como una traducción análoga de este principio indígena; que permitiría rehabilitarlas tradiciones ancestrales de los pueblos autóctonos yromper 
las formas contemporáneas de colonización simbólica. Por lo tanto, en la senda del Buen vivir"se difundió un espíritu afín orientado a descolonizar el pensamiento propio y romper con las cadenas que mantenían esos saberes subordinados, donde posiblemente el caso más claro sea la discusión sobre la colonialidad del poder impulsada por Aníbal Quijano. Bajo esa influencia, el Buen vivir invocaba la recuperación de un saber indígena, y de vivencias, que reaccionaban en contra del desarrollo" (Gudynas \& Acosta, 2011: p. 106).

De hecho, muchos intelectuales asociados con el grupo Modernidad/Colonialidad han escrito sobre el Buen vivir con mayor o menor énfasis. Como hemos señalado, en este grupo, el Buen vivir se interpreta como una oportunidad para la descolonización del conocimiento. Parece lógico que esta posición se desarrolle porque el Buen vivir se presenta como una alternativa al desarrollo. En otros términos, esta posición opone diametralmente el Buen vivir y la modernidad (definida exclusivamente en términos de difusionismo europeo) y utiliza el Buen vivir como palanca para apoyar la lucha anti-moderna/anti-colonial.

Evidentemente, este enfoque parece menos consistente con la visión de un mundo fundamentalmente plural. Construye una interpretación del Buen vivir encerrada sobre sí misma y que difícilmente puede ser pertinente en otros contextos culturales y geográficos. En ese sentido, en lugar de proponer una nueva base filosófica para la organización de la vida colectiva (como alternativa a la ideología occidental de progreso, pero sin rechazar completamente la modernidad), esta crítica fundamentalista permanece anclada en la dicotomía estéril universalismo/particularismo. De hecho, en esta concepción la multiculturalidad es concebida como una serie de proyectos pre-modernos, modernos y posmodernos particulares que no se cruzan. En este contexto, ¿cómo el Buen vivir podría participar eficazmente en el debate mundial sobre el desarrollo si adopta a priori una posición radical de rechazo de los modelos culturales promovidos por otros grupos?

Por otro lado (de acuerdo con la segunda posición “moderada”), los intelectuales directa o indirectamente involucrados en los procesos de cambio político están construyendo una versión del Buen vivir más dialógica e integradora. Este es claramente el caso de Alberto Acosta. Este es también el caso de Pablo Dávalos en Ecuador y David Choquehuanca Céspedes o Pablo Mamani Ramírez, entre otros en Bolivia. Estos autores más “moderados” también hacen hincapié en la oportunidad del Buen vivir para deconstruir el modelo de desarrollo actualmente dominante, sin ser necesariamente incompatible con la modernidad (considerada aquí como "múltiple” y/o “entramada”). Aquí, la atención se centra más bien en el hecho de que "la discusión sobre el Buen vivir no puede limitarse a las realidades de los Andes” (Acosta, 2010) y en la necesidad de proyectar esta nueva propuesta a nivel global.

Estos autores insisten sobre todo en el hecho de que el Buen vivir es un concepto en construcción, directamente relacionado con una forma de 
diálogo intercultural alrededor de la cuestión fundamental de la sustentabilidad (y otros problemas fundamentales de la vida colectiva); un diálogo interdiscursivo que incluye a otros discursos críticos (occidentales y no occidentales) del campo discursivo del desarrollo sustentable. Así, según los autores moderados, los casos de Bolivia y Ecuador muestran que "está en marcha un diálogo con las tradiciones culturales indígenas, y que ellas pueden crear o re-crear nuevas conceptualizaciones adaptadas a las circunstancias actuales. Esto no es un simple regreso a las ideas de un pasado lejano. Por otro lado, en ese diálogo también intervienen algunas tradiciones occidentales que han cuestionado distintos presupuestos de la modernidad dominante" (Gudynas \& Acosta, 2011: p. 106). En contraste con la postura de la descolonización del saber, esta sugerencia destaca el potencial dialógico del Buen vivir sin oponerse de manera abrupta a la modernidad.

Estas versiones académicas del discurso del Buen vivir se asemejan a las teorías "post-desarrollistas" (que oscila entre el particularismo y el pluralismo), directamente relacionada a las teorías post-estructuralistas y entre sus principales representantes están algunos intelectuales progresistas latinoamericanos (como Leonardo Boff, Gustavo Esteva, Arturo Escobar, Alberto Acosta, Eduardo Gudynas, etc.) y europeos (como José María Tortosa, Joan Martínez Alier, etc.) vinculados al ambientalismo, a las críticas al desarrollo y a una serie de movimientos sociales que se alimentan del (y alimentan el) Buen vivir. Los elementos centrales de esta corriente "postestructuralista” son la preservación de la naturaleza y la construcción conjunta del Buen vivir (y no exclusivamente el Sumak Kawsay) que es central; un proyecto que iría "más allá del desarrollo” (Gudynas, 2011), que sería una "utopía por (re)construir" (Acosta, 2011). Esta construcción se quiere participativa y plural, en la intersección de las concepciones indígenas, campesinas, sindicalistas, cooperativistas, feministas, pacifistas, ecologistas, socialistas, teólogo-liberacionista, descolonial, etc. Esta corriente considera que distintas apropiaciones del Buen vivir pueden coexistir en un mundo plural. Nos encontramos entonces ante una concepción del Buen vivir que resuena con los enfoques plurales de la modernidad y que supera la dicotomía universalismo-particularismo.

En relación al desarrollo sustentable, para esta corriente postestructuralista, el Buen vivir implica necesariamente la superación del dualismo Sociedad-Naturaleza. A propósito de ello, Eduardo Gudynas habla de giro biocéntrico: "el buen vivir de los seres humanos es posible si, y sólo si, se asegura la supervivencia y la integridad de la trama de vida de la Naturaleza” (Gudynas, 2009: p. 52). Así, por un lado, esta corriente se inclina hacia el pathos de la ecología profunda, considerando la "trama de vida de la naturaleza” y la Tierra como un solo organismo. Al mismo tiempo, se aleja de esta tendencia, ya que no subordina el ser humano a la naturaleza, sino que reconoce su interdependencia y la necesidad de armonización basada en el principio de reciprocidad ${ }^{13}$ : la naturaleza no es simplemente el espacio que rodea; es parte de los seres humanos y viceversa. Por otra parte, y nuevamente en línea con otros discursos críticos a nivel mundial, el Buen 
vivir implica una transformación de las estructuras económicas y las relaciones de poder de inter e intra-sociedad. En este sentido, rivaliza con las interpretaciones dominantes de desarrollo sustentable que, en la práctica, defienden el status quo o la reforma (incremental) del sistema existente, sin cuestionar los legados de modernización o del desarrollo eurocéntrico en su conjunto.

Como hemos señalado, a más de 25 años de la consagración del desarrollo sustentable, las polémicas que le dieron luz permanecen prácticamente intactas (si no se han profundizado). Las versiones académicas del Buen vivir parten de este punto crítico y buscan re-contextualizar la reflexión colectiva acerca de las derivas socio-económicas y ecológicas del modelo de desarrollo actual y la capacidad de responder al imperativo de la sustentabilidad. En este sentido, en relación con la tipología de John Dryzek (2005), se oponen abiertamente a los discursos de tipo "prometeico" (que apoyan el status quo), e introducen una síntesis entre el discurso "survivalista” (de los años 1970) y el "Radicalismo verde". Siguiendo John Dryzek, el discurso survivalista instala la idea fundamental de límites y propone una reorientación radical del paradigma de crecimiento infinito. Sin embargo, sigue siendo prosaico porque las soluciones que proponese inscriben en opciones derivadas del industrialismo (particularmente en relación al papel atribuido a las élites económicas, administrativas y científicas). Para la corriente “post-estructuralista” del Buen vivir, estas reformas son insuficientes. Al contrario, es necesario salir de las estructuras de la sociedad industrial e instaurar una nueva manera de concebir el entorno natural y las relaciones entre sus componentes (y eso, de manera democrática). Siguiendo el cuadro propuesto por Bill Hopwood \& al. (2005) estamos frente a una versión transformacionista radical claramente incluida en el campo discursivo del desarrollo sustentable.

Más allá de esta categorización del discurso en tres versiones distintas, aparece evidente que son las sinergias entre estas variantes las que inscriben el Buen vivir en el campo discursivo del desarrollo sustentable y encuentran una cierta resonancia a nivel mundial.

\section{Conclusiones sobreel discurso y las traduccionespolíticas del Buen vivir}

La emergencia del Buen vivir viene a reforzar las múltiples voces que denuncianlos límites etnocéntricos y antropocéntricos de las concepciones eurocéntricas del desarrollo y del progreso; heredadas por algunas versiones del discurso del desarrollo sustentable. Estos discursos dominantes del desarrollo sustentablese inclinan hacia la conservación del orden socio-económico mundial a pesar de la evidencia de su insustentabilidad. Sin embargo, si las versiones conservadores del desarrollo sustentable siguen siendo dominantes, no monopolizan el espacio discursivo global del campo, como podemos verlo con elflorecimiento cre- 
ciente de discursos alternativos (y de sus coaliciones). En este sentido, los discursos del Buen vivir presentan un potencial prometedor, en la medida en que se conciban en diálogo con las diferentes alternativas contemporáneas de la sustentabilidad, y no como el eco nostálgico de un pasado lejano. En este sentido, proponen un nuevo camino hacia una reforma de la civilización en tensión y en continuidad con las múltiples contribuciones al campo discursivo del desarrollo sustentable(Vanhulst \& Beling, 2013a, 2013b, 2014).

Hemos visto que el surgimiento delBuen vivircomienza a partir de 2008.Aparece en la senda de los movimientos indígenas dela década de 1990 y simultáneamente al surgimiento de gobiernos de izquierda "progresista", al desencanto creciente frente al ideal del desarrollo, y al fortalecimiento de los nuevos movimientos sociales internacionales. De hecho, hemos visto también que el Buen vivir ha tenido una cierta resonanciaa nivel internacional y que los diferentes grupos sociales (heterogéneos) se han apropiado de este discursopara defender sus intereses en materia de protección del medio ambienteo de reconocimiento de los valores y prácticas de grupos marginados.

En cuanto al contenido, las raíces del Buen vivirse encuentran enalgunos principios de las cosmologías de los pueblos indígenas de los Andes. Estos principios estánreinterpretados poractores contemporáneos y traducidos en un discurso moderno quepropone un modelo cultural alternativo y se presenta como una utopía frente a los efectos deletéreos de la sociedad industrial y del capitalismo neoliberal en los distintos aspectos que constituyen la trama del orden social (modo de producción, regulación social, conocimiento y sustentabilidad). La dimensiónindígena del Buen vivir, operacomo una inspiraciónextraída delasculturas localesque no haborradopor completola ética, laconciencia yla prudenciafrente a la naturaleza (que la civilización industrialtiendeeliminar). Esta dimensión inscribe elBuen viviren el conjunto más amplio delos movimientos sociales indígenas de finales del siglo XXque participan delos debates contemporáneos sobre cuestiones socialesy ambientales.

Algunas interpretaciones intrínsecamente relacionadas a estas raíces indígenas tienden a esencialisarel Buen vivir. Esta forma de fundamentalismo tiende a auto-excluirse de los diálogos potenciales con otros discursos modernos. Sin embargo, ante la ausencia de una definición clara, el Buen vivir se convirtió en una referencia para diferentes discursos y prácticas que buscan una alternativa a los modelos de desarrollo actuales. Así, entra naturalmente en sinergia con algunas propuestas críticas anteriores que se unen a esta nueva referencia, proveniente de los márgenes de los centros de poder (y entre otros, los discursos y las prácticas de la economía social/solidaria, del ecosocialismo, del decrecimiento, de la ecología profunda, etc.), pero también con los discursos críticos de la región de América Latina (entre otros los de Enrique Leff, Arturo Escobar, Carlos Walter Porto-Gonçalves, Leonardo Boff, etc.). Fundamentalmente, el Buen vivir se presenta como un discurso crítico en el campo discursivo de 
desarrollo sustentable, cercano al radicalismo verde (Dryzek, 2005) y a los discursos transformacionistas(Hopwood \&al., 2005). Por lo tanto, se diferencia de las versiones más conservadoras del discurso del desarrollo sustentable, tal como es compatible con algunas versiones transformadoras. De ahí, concuerda naturalmente con varios discursos contemporáneos que buscan transformar las formas de organización social y los modos de producción y consumo con el fin de responder al imperativo de la sustentabilidad.

Así, más allá de las distorsiones fundamentalistas (que buscan restablecer una visión esencialista de un pasado ancestral), y pese al riesgo latente de cooptación por intereses políticos más o menos conservadores, el principal interés de Buen vivir reside en su potencial de diálogo con la modernidad y las formas actuales de desarrollo. El vínculo explícito entre justicia social, valoración de saberes y prácticas históricamente subordinadas y respeto por el medio ambiente es singular del Buen vivir (aunque encontramos esta síntesis bajo otras formas en las corrientes eco-socialista, eco-feminista, de la justicia ambiental y de los movimientos anti-capitalistas, los cuáles entran, como hemos visto, en sinergia con el discurso del Buen vivir). En este sentido, los discursos del Buen vivir traen una nueva perspectiva a los desafíos del desarrollo sustentable en los planos económico, social y ambiental; y refuerzansimultáneamente las propuestas con las que entra en coalición.

Loque se observa empíricamente con el análisis del Buen vivir, es que se configuró como un sub-campo en el campo discursivo del desarrollo sustentable (como espacio de lucha entre diferentes maneras de abordar el problema de la sustentabilidad) con diferentes posiciones que buscan institucionalizarse y orientar las trayectorias de desarrollo de las sociedades de manera sustentable. Por lo tanto, un enfoque pluralista parece más pertinente que los extremos universalistay particularista para dar cuenta de esta situación.

Siguiendo este enfoque pluralista, hemos visto,a partir delas contradicciones derivadas de las traducciones políticas, que las transformaciones prácticas relacionadas con el discurso del Buen vivir también dependen de las estructuras de sentido y de los órdenes simbólicos preexistentes y no representan una ruptura definitiva y abrupta con las bases discursivas (normativas y prácticas) anteriores. El potencial delBuen vivir radica ensu capacidad de interactuarcon estos arreglosculturales,socio-políticos y económicospreexistente y con los otros discursos que dibujan desde más de 40 años los senderos bifurcados del desarrollo sustentable. 


\section{Notas}

${ }^{1}$ El paradigma "universalista" se fundamenta en una concepción de las trayectorias de las sociedades como lineales y convergentes hacia un modelo único, hacia un horizonte universal de referencia. La contracara del paradigma universalista es el paradigma "particularista", que se fundamenta en la idea de las trayectorias de las sociedades como distintas y divergentes. Sólo existen horizontes particulares e inconmensurables. En la continuación más reciente de este debate, se distingue una tercera orientación "pluralista" que reconoce la necesidad de encontrar un equilibrio entre estos dos paradigmas, considerando que la antinomia radicalizada universalismo-particularismo conduce a aporías lógicas y morales insuperables (ver por ejemplo las teorías de Arnason, 2003; Domingues, 2006; Eisenstadt, 2000; Therborn, 2003; Wagner, 2008, 2013).

${ }^{2}$ Señalamos que existen algunas publicaciones anteriores (i.a. Medina, 2001; Rengifo, 2002; Viteri Gualinga, 2002) que hablan de Sumak Kawsay o Suma Qamaña. Sin embargo, éstas son más bien cercanas a las versiones indigenistas que de las reelaboraciones del discurso en términos de Buen vivir (ver más abajo).

${ }^{3}$ Hopwood \&al.(2005), proporcionan una valiosa tipología basada en dos ejes principales: en la abscisa, la clásica dicotomía antropocentrismo-ecocentrismo y en la ordenada, otra dicotomía asentada en el continuum desigualdad-igualdad. Además, sugieren una distinción (en línea con Dryzek) entre tres formas de problematizar las instituciones existentes: el status quo, la reforma y la transformación (según el grado de crítica). Siguiendo esta propuesta, el campo discursivo del desarrollo sostenible está conformado por discursos que incluyen no sólo el medio ambiente sino también la justicia social.

${ }^{4}$ Confederación de Nacionalidades Indígenas de Ecuador (desde 1986)

${ }^{5}$ Confederación de Pueblos Indígenas de Bolivia (desde 1982)

${ }^{6}$ Confederación Andina de Organizaciones Indígenas (fundada en julio 2006 en Cuzco, Perú, por los pueblos quechuas, ichwas, aymaras, mapuches, cymbis, saraguros, gumbinos, koris, lafquenches, urus, entre otros; pero estos pueblos indígenas empezaron a reunirse a nivel regional desde el año 2000 con la primera Cumbre Continental de los Pueblos y Nacionalidades Indígenas de AbyaYala en la ciudad de Teotihuacan en México).

${ }^{7}$ Por ejemplo en el caso de Ecuador: las ONG ambientales como Acción Ecológica, Fundación Pachamama, Fundación Natura y la red internacional Oilwatch. Estas ONG, que trabajan con las comunidades autóctonas, han tenido un papel importante en la discusión sobre la transición a una economía “post-petrolera” en la agenda política; esto, a partir de 1993 con una demanda contra Texaco/Chevron, más conocido como el "juicio del siglo". En un contexto más favorable a la expansión de la frontera de explotación de petróleo, los movimientos sociales locales (con el apoyo de Oilwatch) propusieron una moratoria sobre la extracción de petróleo en la región centro-sur de la Amazonía ecuatoriana. Esta propuesta, esbozada en diversos espacios y foros, obtuvo un estatus público tras la publicación del libro "El Ecuador post-petrolero" en 2000 (Acosta, 2000). En 2003, la propuesta de moratoria sobre el petróleo se presentó oficialmente al Ministerio de Medio Ambiente por varias ONG ambientales. Poco después, en 2005, durante un evento Oilwatch en Italia, el documento "An eco- 
logicalcallforconservation, climate and rights" (una llamada eco-lógica para la conservación, el clima y los derechos) hace hincapié en la necesidad de combinar los temas de conservación de la biodiversidad, cambio climático y derechos de los pueblos indígenas en una estrategia común para salvar las áreas de alta diversidad, y sugiere la aplicación de esta estrategia a la Reserva de la Biosfera Yasuní. Esto es la antesala de la Iniciativa Yasuní, presentada oficialmente por el gobierno ecuatoriano en 2007, puesta en marcha (con el apoyo del PNUD) en 2010 y finalmente cancelada en agosto de 2013.

${ }^{8}$ Ver el "Llamamiento desde los pueblos indígenas frente a la crisis de civilización occidental y capitalista" que articula los temas de la siguiente manera: "Criar a la madre tierra y dejarse criar por ella. Crianza del agua como derecho humano fundamental y no su mercantilización. Descolonialidad del poder con el "Mandar obedeciendo”, autogobierno comunitario, Estados Plurinacionales, Autodeterminación de los Pueblos, unidad en la diversidad como otras formas de autoridad colectiva. Unidad, dualidad, equidad y complementariedad de género. Espiritualidades desde lo cotidiano y diverso. Liberación de toda dominación o discriminación racista/etnicista/sexista. Decisiones colectivas sobre la producción, mercados y economía. Descolonialidad de las ciencias y tecnologías. Expansión de la reciprocidad en la distribución de trabajo, de productos, de servicios. Desde todo lo anterior producir una nueva ética social alternativa a la del mercado y del lucro colonial/capitalista”.

${ }^{9}$ Por otra parte, la ayuda financiera y el apoyo técnico para estos programas provienen entonces de varias organizaciones internacionales, como la Agencia Alemana de Cooperación Internacional para el Desarrollo (GIZ) y el Banco Interamericano de Desarrollo (BID).

${ }^{10}$ Ver : http://www.prometeo.com.ec/(notamos que es el mismo nombre inscribe el proyecto de la sociedad del conocimiento en un ideal más bien alejado del Buen vivir y cercano a la lógica moderna eurocéntrica prometeana)

${ }^{11}$ Ver : http://floksociety.org/ (el proyecto FlokSocietytiene como objetivo estimularel intercambio abiertode conocimientos científicos ybuscainscribirse en elBuen vivir, ofreciendo una manera de“conocer bien”unBuenconocer)

${ }^{12}$ Ya hemos mencionado algunos representantes del mundo académico en la introducción y en las dos corrientes anteriores. Aquí proponemos un punto específico sobre los investigadores que nutren los discursos del Buen vivir considerando que forjan una corriente que no es asimilable a las otras dos a pesar de que la separación no es muy nítida. Así, está claro que los intelectuales no están desconectados ni de la sociedad civil, ni de las organizaciones indígenas, ni de la esfera política.

${ }^{13}$ Como se señaló anteriormente, esta relación "armoniosa” descansa en el principio de mutualidad, más que de competencia, entre las distintas comunidades y entre las comunidades y el cosmos. Siguiendo la cosmología indígena andina, esta idea de reciprocidad se incluye en los principios de Rari-Rari, Ruray, MakiMaki o Yachay; directamente relacionada al Sumak Kawsay(para mayor detalles sobre este tema, consulte Beling, Gomez, \& Vanhulst, 2014; Estermann, 2006). 


\section{Bibliografía}

Acosta, A. (Ed.). (2000), El Ecuador Post Petrolero. Oilwatch, Acción Ecológica \& ILDIS. Quito.

Ídem (2010), “Sólo imaginando otros mundos, se cambiará éste - Reflexiones sobre el Buen Vivir”. Revista Sustentabilidad(es), (2).

Ídem (2011), “El buen (con)vivir, una utopía por (re)construir: alcances de la Constitución de Montecristi.” OBETS. Revista de Ciencias Sociales, 6(1).

Ídem (2013), “Las tribulaciones de la Iniciativa Yasuní-ITT”. Letras Verdes. Revista Latinoamericana de Estudios Socioambientales, 0(6), 19-22.

Amin, S., \& Houtart, F. (2002), Mondialisation des résistances et des luttes. Editions L'Harmattan.

Arnason, J. P. (2003), Civilizations in Dispute: Historical Questions and Theoretical Traditions. BRILL.

Banco Central de Ecuador. (2014), Reporte del sector petrolero - IV trimestre de 2013. Banco Central de Ecuador - Dirección de Estadística Económica. Quito.

Beling, A. E., Gomez, F., \& Vanhulst, J. (2014), “Del Sumak Kawsay al Buen vivir: filosofía andina como base para una racionalidad ambiental moderna”. In C. M. Gómez (Ed.), La religión en la sociedad postsecular. Transformación y relocalización de lo religioso en la modernidad tardía. Universidad del Rosario - Centro de Estudios Teológicos y de las Religiones (CETRE).Bogotá.

Capitán, A. L. H., \& Guevara, A. P. C. (2014), “Seis debates abiertos sobre el sumak kawsay”. Íconos: Revista de Ciencias Sociales, (48), 25-40.

Caria, S., \& Domínguez, R. (2014a), “El porvenir de una ilusión: la ideología del Buen vivir”. América Latina Hoy: Revista de Ciencias Sociales, 67, 139-163.

Ídem (2014b), Si del cielo no te caen limones... sigue sacando petróleo. Actas de Congreso: II Congreso Internacional de Estudios del Desarrollo "Perspectivas alternativas del desarrollo", Junio, Universidad de Huelva. España.

Correa, R. (2012), Ecuador: De Banana Republic a la No República. Penguin Random House Grupo Editorial Colombia.

Cubillo-Guevara, A. P., Hidalgo-Capitán, A. L., \& Domínguez-Gómez, J. A. (2014), "El pensamiento sobre el Buen Vivir. Entre el indigenismo, el 
socialismo y el postdesarrollismo”. Revista Del CLAD Reforma Y Democracia, (60), 27-58.

De Sousa Santos, B. (2014), ¿La Revolución ciudadana tiene quién la defienda? Recuperado del http://blogs.publico.es/espejos-extranos/2014/05/ 09/la-revolucion-ciudadana-tiene-quien-la-defienda/

Domingues, J. M. (2006), Modernity reconstructed. University of Wales Press.

Dryzek, J. S. (2005), The politics of the earth: environmental discourses. Oxford University Press.

Eisenstadt, S. N. (2000), “Multiple Modernities”. Daedalus, 129(1), 1-29.

Estermann, J. (2006), Filosofía andina: sabiduría indígena para un mundo nuevo. Instituto Superior Ecuménico Andino de Teología.

Fernández, B., Pardo, L., \& Salamanca, K. (2014), “El buen vivir en Ecuador: ¿marketing político o proyecto en disputa? Un diálogo con Alberto Acosta”. Íconos - Revista de Ciencias Sociales, 0(48), 101-117.

García, J., Lozano, A., Olivera, J., \& Ruiz, C. (2004), Aprender en la sabiduría y el buen vivir (UNESCO). Amawtay Wasi Pakta kawsaypak Sumak Yachay Wasi. Quito.

Gudynas, E. (2009), “La dimensión ecológica del buen vivir: entre el fantasma de la modernidad y el desafío biocéntrico”. Obets, (4).

Ídem (2010), “Si eres tan progresista ¿Por qué destruyes la naturaleza? Neoextractivismo, izquierda y alternativas”. Ecuador Debate, (79), 61-81.

Ídem (2011), “Buen vivir: germinando alternativas al desarrollo”. América Latina En Movimiento.

Ídem (2012), “Estado compensador y nuevos extractivismos: Las ambivalencias del progresismo sudamericano”. Nueva Sociedad, (237), 128146.

Ídem (2013), “La disputa por el buen vivir”. Diagonal Periódico. Madrid.

Ídem (2014a), "Buen vivir: sobre secuestros, domesticaciones, rescates y alternativas”. In A. Oviedo Freire (Ed.), Bifurcación del buen vivir y el sumak kawsay (pp. 23-45). Yachay. Quito.

Ídem (2014b), “El postdesarrollo como crítica y el Buen Vivir como alternativa”. In G. C. Delgado Ramos, Buena Vida, Buen Vivir: imaginarios alternativos para el bien común de la humanidad (pp. 61-95). CEIICH - UNAM. México. 
Gudynas, E., \& Acosta, A. (2011), “El buen vivir o la disolución de la idea del progreso”. In M. Rojas (Ed.), La medición del progreso y el bienestar. Propuestas desde América Latina (pp. 103-110). Foro Consultivo Científico y Tecnológico de México. México.

Hidalgo-Capitán, A. L., Guillen, A., Vega, F., Mancero, N., Encalada, D., \& Ávila, J. (2012), El Buen Vivir. La (re)creación del pensamiento del PYDLOS. PYDLOS. Cuenca.

Hollender, R. (2012), "Política ambiental de los países "progresistas” en Latinoamérica: Buen Vivir vs. Neo-Extractivismo”. Observatorio de Multinacionales En América Latina. Recuperado de http://omal.info/ spip.php?article4661

Hopwood, B., Mellor, M., \& O’Brien, G. (2005), “Sustainable development: mapping different approaches”. Sustainable Development, 13(1), 38-52.

Huanacuni Mamani, F. (2010), Buen Vivir / Vivir Bien. Filosofía, políticas, estrategias y experiencias regionales andinas. Coordinadora Andina de Organizaciones Indígenas (CAOI).

IPCC. (2014), Fifth Assessment Report on Climate Change. International Panel on Climate Change.

Jiménez, R. (2011), Recovering and values other ethical pillars. Buen Vivir. Forum for a new World Governance.

Joseph, S. (2012), "Protracted Lawfare: The Tale of Chevron Texaco in the Amazon”. Journal of Human Rights and the Environment, 3(1), 70-91.

Kauffman, C., \& Martin, P. (2014), “Scaling up Buen Vivir: globalizing local environmental governance from ecuador”. Global Environmental Politics, 14(1), 40-58.

Kimberling, J. (2005), “Indigenous Peoples and the Oil Frontier in Amazonia: The Case of Ecuador, Chevrontexaco, and Aguinda v. Texaco”. New York University Journal of International Law and Politics, 38, 413.

Loera Gonzalez, J. J. (2015), Los buenos vivires; tensión entre dos fuerzas. Reportepresentadoal IV Congreso de Cultura y Educación para la Integración de América Latina (CEPIAL), enero 2015, Osorno.

Macas, L. (2010), “Sumak Kawsay: la vida en plenitud”. América Latina En Movimiento, (452), 14-16.

Maldonado, L. (2010), El Sumak Kawsay / Buen Vivir / Vivir Bien. La experiencia de la República del Ecuador. Escuela de Gestión Pública Plurinacional del Ministerio de Educación de Bolivia. 
Martinez-Alier, J. (2008), No sé si hay un ecologismo infantil pero sí creo que hay un desarrollismo senil - Entrevista con Joan Martinez-Alier (por Marc Saint-Upéry). Bolivia. Consultado en http://www.rebelion.org/ noticia.php?id=100428

Martin, P. (2011), “Global Governance from the Amazon: Leaving Oil Underground in Yasuní National Park, Ecuador”. Global Environmental Politics, 11(4), 22-42.

Martin, P., \& Wilmer, F. (2008), “Transnational Normative Struggles and Globalization: The Case of Indigenous Peoples in Bolivia and Ecuador”. Globalizations, 5(4), 583-598.

Medina, J. (Ed.). (2001), Suma qamaña: la comprensión indígena de la buena vida. PADEP/GTZ.

Oviedo Freire, A. (2013), Buen Vivir Vs Sumak Kawsay. 2013: Ciccus. Consultado en http://www.cuspide.com/9789876930369/Buen+ Vivir+Vs+Sumak+Kawsay/

Ídem (2014), Bifurcación del buen vivir y el sumak kawsay. Yachay. Quito. PROECUADOR (2014), Boletin Comercial. PROECUADOR.

Radcliffe, S. (2012), "Development for a postneoliberal era? Sumak kawsay, living well and the limits to decolonisation in Ecuador". Geoforum, 43, 240-249.

Rengifo, G. (2002), Allin Kawsay. El bienestar en la concepción Andino Amazónica. PRATEC. Perú.

SENPLADES (2009), Plan Nacional para el Buen Vivir 2009-2013: Construyendo un Estado Plurinacional e Intercultural (p. 520). SENPLADES. Quito, Ecuador.:

Ídem (2013), Plan Nacional para el Buen Vivir 2013-2017: Todo el mundo mejor. SENPLADES. Quito, Ecuador.

Steffen, W., Richardson, K., Rockström, J., Cornell, S. E., Fetzer, I., Bennett, E. M., Sörlin, S. (2015), "Planetary boundaries: Guiding human development on a changing planet”. Science.

Svampa, M. (2013), “ ‘Consenso de los Commodities’ y lenguajes de valoración en América Latina“. Nueva Sociedad, (244), 30-46.

Therborn, G. (2003), “Entangled Modernities”. European Journal of Social Theory, 6(3), 293-305.

United Nations (2014), Millennium Development Goals Reports. 


\section{United Nations.}

Vanhulst, J., \& Beling, A. E. (2013a), Buen vivir: la irrupción de América Latina en el campo gravitacional del desarrollo sostenible. REVIBEC - Revista Iberoamericana de Economía Ecológica, 21, 15-28.

Ídem (2013b), “El Buen vivir: una utopía latinoamericana en el campo discursivo global de la sustentabilidad”. Polis. Revista Latinoamericana, (36). Retrieved from http://polis.revues.org/9638

Ídem (2014), "Buen vivir: Emergent discourse within or beyond sustainable development?”, Ecological Economics, 101, 54-63.

Viteri Gualinga, C. (2002), “Visión indígena del desarrollo en la Amazonía”. Polis. Revista Latinoamericana, (3).

Wagner, P. (2008), “Modernity as experience and interpretation: a new sociology of modernity”. Polity.

Ídem (2013), “Redefiniciones de la modernidad”. Revista de Sociología (FACSO), (28).

Walsh, C. (2010), “Development as Buen Vivir: Institutional arrangements and (de)colonial entanglements”. Development, 53(1), 15-21.

Yashar, D. J. (2005), Contesting Citizenship In Latin America: The Rise Of Indigenous Movements And The Postliberal Challenge. Cambridge University Press. 